\title{
Identification of a subset of patients with scleroderma with severe pulmonary and vascular disease by the presence of autoantibodies to centromere and histone
}

\author{
Liam Martin, John D Pauls, J Paul Ryan, Marvin J Fritzler
}

\begin{abstract}
Objectives-The role of autoantibodies in the investigation and management of rheumatic diseases is well recognised. The objective of this study was to determine the clinical significance of the cooccurrence of antibodies to centromere and histone in serum samples from patients investigated for systemic rheumatic diseases.

Methods-Serum samples from 1316 consecutive patients were screened for antinuclear antibodies and the clinical findings in patients with antibodies to centromere alone were compared with those with antibodies to both centromere and histone.

Results-Twenty six patients had antibodies to centromere. Fourteen patients had antibodies to centromere alone and 12 patients had antibodies to centromere and histone. Four of the 12 patients with antibodies to centromere and histone had diffuse scleroderma with severe pulmonary or vascular disease.

Conclusions-A subset of patients with scleroderma with antibodies to centromere and histone has been identified retrospectively, who have severe pulmonary or vascular disease. It will be of interest to follow up the clinical course of other patients with scleroderma who have both antibodies for the development of pulmonary or vascular disease.
\end{abstract}

(Ann Rheum Dis 1993; 52: 780-784)

Autoantibodies have been shown to be important in the investigation of systemic rheumatic diseases. Some autoantibodies act as markers of disease. For example, Smith (Sm) antibodies are found specifically in the serum of patients with systemic lupus erythematosus $(\mathrm{SLE})^{1}$ and antibodies to Scl-70 (topoisomerase 1) are diagnostic of scleroderma. ${ }^{2}$ Other antibodies which may be of diagnostic significance are those directed against the (H2A-H2B)-DNA dimer in drug induced lupus $^{3}$ and against SS-A/Ro antigens in neonatal lupus. ${ }^{4}$ Autoantibodies may also help in determining the prognosis of patients with systemic rheumatic diseases. Centromere antibodies are found in a high proportion of patients with the CREST variant or limited form of scleroderma, ${ }^{6-8}$ which is associated with a better prognosis than the diffuse form of the disease. ${ }^{8-10}$

In serum samples from some patients more than one autoantibody may be identified. This is most common in SLE and may have clinical implications. ${ }^{11}$ Apart from one study where the co-occurrence of antibodies to SS-A/Ro and SS-B/La in SLE was reported to be associated with a lower incidence of renal disease, ${ }^{12}$ however, the clinical significance of coexisting antibodies has received little attention.

In this paper we report the results of our clinical observations in a group of 12 patients who had antibodies to both histone and centromere antigens. We reviewed the clinical findings in patients with antibodies to centromere alone and in those with antibodies to both centromere and histone. Our results showed that most patients with antibodies to centromere had scleroderma, either the diffuse form or the CREST variant of this disease. ${ }^{13}$ When the two antibodies were present in diffuse scleroderma the patients had severe pulmonary or vascular disease. Our findings suggest that the presence of antibodies to centromere and histone in patients with the scleroderma spectrum of diseases may indicate a poor prognosis.

\section{Patients and methods}

SERUM SAMPLES AND ANTIBODY TESTING

Over a 12 month period we studied 1316 serum samples referred to the rheumatic disease unit laboratory at the University of Calgary for antinuclear antibody testing. Antinuclear antibodies were detected by indirect immunofluorescence on $\mathrm{HEp}-2$ cells (Immunoconcepts, Sacramento, CA, USA) as previously described. ${ }^{14} 15$ Briefly, serum samples were diluted $1 / 40$ in phosphate buffered saline (PBS) and incubated with HEp-2 cells at room temperature for 30 minutes in a moist chamber. After washing in PBS, antibody reactivity was detected using FITC conjugated polyvalent antihuman IgG, IgA, and IgM (Calbiochem-Behring, Mississauga, Ontario, Canada) with a fluorescein to protein ratio of 3.9/1. The cells were washed, mounted in glycerol, and observed using a Zeiss fluorescence microscope. Immunofluorescence staining was scored from $1+$ to $4+$ and all positive serum samples were titrated to the endpoint. Antibodies to double stranded DNA
Correspondence to: Dr Martin. 
Table 1 Clinical data on 26 patients with antibodies to centromere

\begin{tabular}{|c|c|c|c|c|}
\hline Patient No & Age (years) & Diagnosis & $\begin{array}{l}\text { Disease duration } \\
\text { (years) }\end{array}$ & Clinical findings \\
\hline \multicolumn{5}{|c|}{ Patients with antibodies to centromere/histone } \\
\hline 1 & 61 & Scl, diffuse & 15 & Sk, vasculature \\
\hline 2 & 67 & Scl, diffuse & 20 & $\mathrm{Sk}, \mathrm{H}, \mathrm{P}$ \\
\hline 3 & 46 & Scl, diffuse & 20 & Sk, H, P \\
\hline 4 & 36 & Scl, diffuse, SLE & 16 & Sk, H, P, GI \\
\hline 5 & 67 & CREST & 12 & $\mathrm{R}, \mathrm{E}$ \\
\hline 6 & 68 & CREST & 20 & $\mathrm{C}, \mathrm{R}, \mathrm{E}, \mathrm{S}, \mathrm{T}$ \\
\hline 7 & 52 & CREST & 5 & $\mathrm{C}, \mathrm{R}, \mathrm{S}, \mathrm{T}$ \\
\hline 8 & 41 & CREST & 3 & $R, S, T$ \\
\hline 9 & 47 & CREST & 10 & $\mathrm{R}, \mathrm{E}, \mathrm{T}$ \\
\hline 10 & 76 & SLE & 10 & Sk, Ar, Pl \\
\hline 11 & 86 & RA, SjS & 30 & Ar, Xero \\
\hline 12 & 71 & An, Leuk & 1 & \\
\hline \multicolumn{5}{|c|}{ Patients with antibodies to centromere } \\
\hline 1 & 40 & CREST & 5 & $\mathrm{R}, \mathrm{E}, \mathrm{S}$ \\
\hline 2 & 47 & CREST & 12 & $\mathrm{R}, \mathrm{E}, \mathrm{S}, \mathrm{T}$ \\
\hline 3 & 53 & CREST & 3 & $\mathrm{R}, \mathrm{S}, \mathrm{T}$ \\
\hline 4 & 43 & CREST & 16 & C, R, E, S, T \\
\hline 5 & 57 & CREST & 11 & R, E, S, T \\
\hline 6 & 60 & CREST & 20 & C, R, E, S, T \\
\hline 7 & 48 & CREST & 20 & $\mathrm{C}, \mathrm{R}, \mathrm{E}, \mathrm{S}, \mathrm{T}$ \\
\hline 8 & 67 & CREST & 20 & $\mathrm{R}, \mathrm{E}$ \\
\hline 9 & 40 & CREST & 4 & $\mathrm{R}, \mathrm{E}, \mathrm{T}$ \\
\hline 10 & 67 & CREST/DM & 20 & $\mathrm{R}, \mathrm{S}, \mathrm{Mus}, \mathrm{Sk}$ \\
\hline 11 & 51 & SjS & 4 & Xero \\
\hline 12 & 56 & R & 20 & \\
\hline 13 & 63 & Stroke & Recent & \\
\hline 14 & 62 & Neutropenia & Recent & \\
\hline
\end{tabular}

All the patients were women. Abbreviations used: $\mathrm{An}=$ anaemia; $\mathrm{Ar}=$ arthritis; $\mathrm{C}=$ calcinosis; $\mathrm{DM}=$ dermatomyositis; $\mathrm{E}=$ oesophagus; $\mathrm{GI}$ = gastrointestinal; $\mathrm{H}=$ heart; Leuk = leukopenia; Mus = muscle weakness; $\mathrm{P}=$ pulmonary; $\mathrm{Pl}=$ thrombocytopenia; $\mathrm{R}=$ Raynaud's phenomenon; $\mathrm{RA}=$ rheumatoid arthritis; $\mathrm{S}=$ sclerodactyly; $\mathrm{Scl}=$ scleroderma; $\mathrm{SjS}=\mathrm{S}$ jögren's syndrome; $\mathrm{Sk}=$ skin tightening; $\mathrm{T}=$ telangiectasia $;$ Xero $=$ dry eyes $/$ mouth

were detected by indirect immunofluorescence using Crithidia luciliae (Immunoconcepts) as substrate and patients' serum at a 1/40 dilution. The results were recorded as positive or negative. ${ }^{16}$ Serum samples were also tested for antibodies to saline extractable nuclear antigens (SSA/Ro, SSB/La, nRNP, Scl-70, and PCNA) by double immunodiffusion using reconstituted rabbit thymus acetone powder (Pel Freez Biologics, Rogus, AR) and bovine spleen extract using methods published elsewhere. ${ }^{14}{ }^{15}$ Precipitin lines were checked for identity by testing against protype serum samples from the Center for Disease Control. Antibodies to histone were detected by an enzyme linked immunosorbent assay (ELISA) ${ }^{17}$ and Western immunoblotting using total calf thymus histone (Worthington Biochemical Corporation, Freehold, NJ, USA) and purified chicken erythrocyte histone preparation, respectively, as substrate. ${ }^{18}$ Serum samples were judged to be positive for histone antibodies by ELISA if the absorbance was greater than two standard deviations (SDs) above the mean absorbance for our normal control population (100 samples). Antibodies to soluble cellular and centromere antigens were detected by immunoblotting using a MOLT-4 (human $\mathrm{T}$ cell lymphoblastic leukaemia, ATCC CRL 1582) whole cell extract as described elsewhere. ${ }^{19}$

PATIENTS

All patients included in this study attended the rheumatic disease unit at the University of Calgary for management of their disease. Clinical information on these patients was obtained by retrospective chart review and from the referring doctor. The patients were diagnosed, where applicable, by criteria

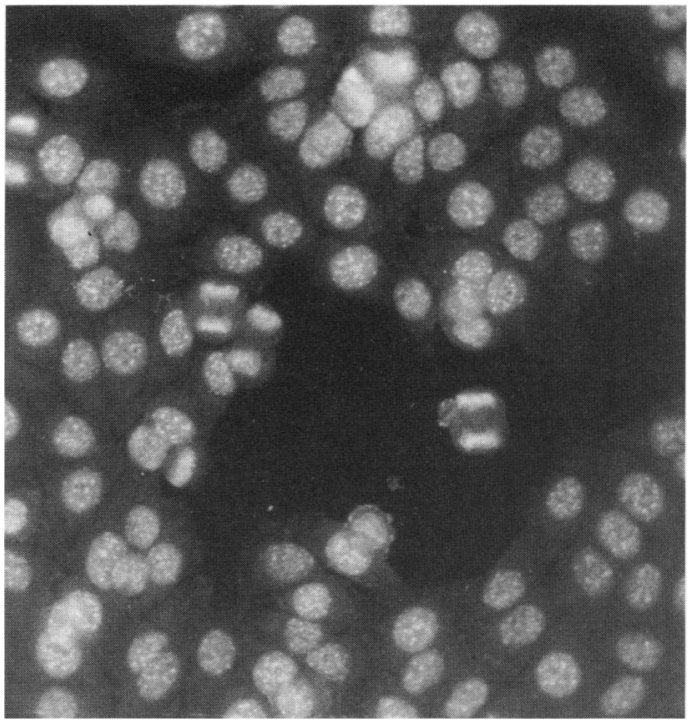

Figure 1 Indirect immunofluorescence pattern on HEp-2 cells produced by serum from a patient at a dilution of $1 / 40$ with antibodies to centromere and histone. The typical speckled pattern of antibodies to centromere is seen on a homogeneous background.

established by the American College of Rheumatology for rheumatoid arthritis (RA), ${ }^{20}$ SLE, ${ }^{21}$ or scleroderma. ${ }^{22}$ The severity of disease as determined by end organ disease was recorded for each patient (table 1 ).

\section{Results}

Of the 1316 serum samples tested over a 12 month period, 26 were found to have antibodies to centromere by indirect immunofluorescence on HEp- 2 cells. The endpoint titre of all serum samples with antibodies to centromere was $>1 / 640$. Twelve serum samples had antibodies to centromere and histone as determined by ELISA or immunoblotting assays. Figure 1 shows an example of the immunofluorescence pattern produced by a serum sample with the two antibodies. The 26 patients positive for antibodies to centromere were divided into two subgroups based on the presence or absence of antibodies to histone.

Table 2 gives the results of the ELISA and immunoblot analyses for these positive 26 patients. Ten of the 12 patients with antibodies to histone were positive by ELISA, 11 by immunoblotting, and nine were positive by both methods. Most of the immunoblot positive patients $(10 / 11)$ reacted with histone (H) 1 or the $\mathrm{H} 1$ variant $\mathrm{H} 5$ ( $\mathrm{H} 1$, five patients; $\mathrm{H} 5$, three patients; $\mathrm{H} 1$ and $\mathrm{H} 5$, two patients), whereas one patient reacted with $\mathrm{H} 2 \mathrm{~B}$. The centromere proteins (CENPs) with which these 12 patients reacted were predominantly CENP-A, B, and D (A, one patient; B, two patients; $A+B$, three patients; $A+D$, one patient, $B+D$, two patients; $A+B+D$, two patients; and $A+B+C$, one patient). Eight of the 14 patients with antibodies to centromere only reacted with CENP-A and $B$, three with CENP-A, B + D, and one each with CENP-B, CENP-C + D, and CENP-A,B + C. Figure 2 gives examples of the immunoblot analysis of patients' serum samples for antibodies to histone and centromere. 
Table 2 Immunoblot and ELISA results in the 26 patients with antibodies to centromere

\begin{tabular}{|c|c|c|c|c|}
\hline Patient & Diagnosis & CENPs & His ELISA & His $L B$ \\
\hline \multicolumn{5}{|c|}{ Patients with antibodies to centromere/histone } \\
\hline & Scl, diffuse & $B$ & + & \\
\hline 2 & Scl, diffuse & B & + & $\mathrm{H} 5$ \\
\hline 3 & Scl, diffuse & A, B & + & $\mathrm{H} 1,2 \mathrm{~B}, 5$ \\
\hline 4 & Scl, diffuse/SLE & A, B & - & \\
\hline 5 & CREST & $A, B, C$ & - & $\mathrm{H} 1,5$ \\
\hline 6 & CREST & A, B & + & $\mathrm{H} 1$ \\
\hline 7 & CREST & B, D & + & H1 \\
\hline 8 & CREST & A, D & + & $\mathrm{H} 1$ \\
\hline 9 & CREST & A & + & H5 \\
\hline 10 & SLE & B, D & + & \\
\hline 11 & $\mathrm{RA}, \mathrm{SjS}$ & A, B, D & + & H1 \\
\hline 12 & & $A, B, D$ & + & $\mathrm{H} 5$ \\
\hline \multicolumn{5}{|c|}{ Patients with antibodies to centromere } \\
\hline 1 & CREST & $A, B, D$ & & \\
\hline 2 & CREST & A, B & & \\
\hline 3 & CREST & A, B & & \\
\hline 4 & CREST & A, B & & \\
\hline 5 & CREST & A, B & & \\
\hline 6 & CREST & A, B & & \\
\hline 7 & CREST & A, B & & \\
\hline 8 & CREST & A, B, D & & \\
\hline 9 & CREST & A, B & & \\
\hline 10 & CREST/DM & C, D & & \\
\hline 11 & & A, B & & \\
\hline 12 & $\mathrm{R}$ & $A, B, C$ & & \\
\hline 13 & Stroke & A, B, D & & \\
\hline 14 & Neutropenia & & & \\
\hline
\end{tabular}

Reactive centromere (CENPs) and histone $(\mathrm{H})$ antigens, as determined by immunoblotting, are shown. Abbreviations: His ELISA = histone ELISA; His IB = histone immunoblot; An = anaemia; CREST = CREST variant; DM = dermatomyositis; $\mathrm{R}=$ Raynaud's phenomenon; $\mathrm{RA}=$ rheumatoid arthritis; $\mathrm{Scl}=$ scleroderma; $\mathrm{SjS}=$ Sjögren's syndrome; $\mathrm{SLE}=$ systemic lupus erythematosus. pulmonary hypertension. This patient also died as a result of right heart failure. Patient 3 was a 46 year old woman who had a nine year history of scleroderma characterised by severe Raynaud's phenomenon, digital ulceration and gangrene, oesophageal dysmotility with reflux and stenosis, diffuse skin disease, and an acute myocardial infarction. At the time of her acute myocardial infarction she was treated with recombinant tissue plasminogen activator, which resulted in a dramatic improvement in the Raynaud's phenomenon and digital ischaemia. ${ }^{23}$ The fourth patient in the diffuse scleroderma group was diagnosed at initial presentation 16 years ago as having SLE and after remission of that disease developed scleroderma. She presented with a history of epilepsy, psychosis, a skin rash, photosensitivity, pleuritis, pericarditis, nephritis, and arthralgias. She had a positive LE cell test and subsequently developed antibodies to $\mathrm{Sm}$, U1-RNP, and SSB/La antigens. At a follow up visit in 1981 she reported increasing problems with Raynaud's phenomenon, digital ulceration, oesophageal reflux, and dyspnoea. Assessment of her respiratory status showed that she had pulmonary fibrosis and pulmonary hypertension. Autoantibody studies showed antibodies to centromere and histone in addition to those previously noted. In 1986 the skin on her fingers became thickened and she developed telangiectasia on her hands and face. In 1988 she had an episode of bowel obstruction and upper gastrointestinal endoscopy showed a dilated duodenum. The patient's clinical course from then on was characterised by diffuse skin thickening, increasing dyspnoea, right sided heart failure, and bowel obstruction. In 1990 she had an operation for a large bowel obstruction and died postoperatively as a result of right heart failure.

digital

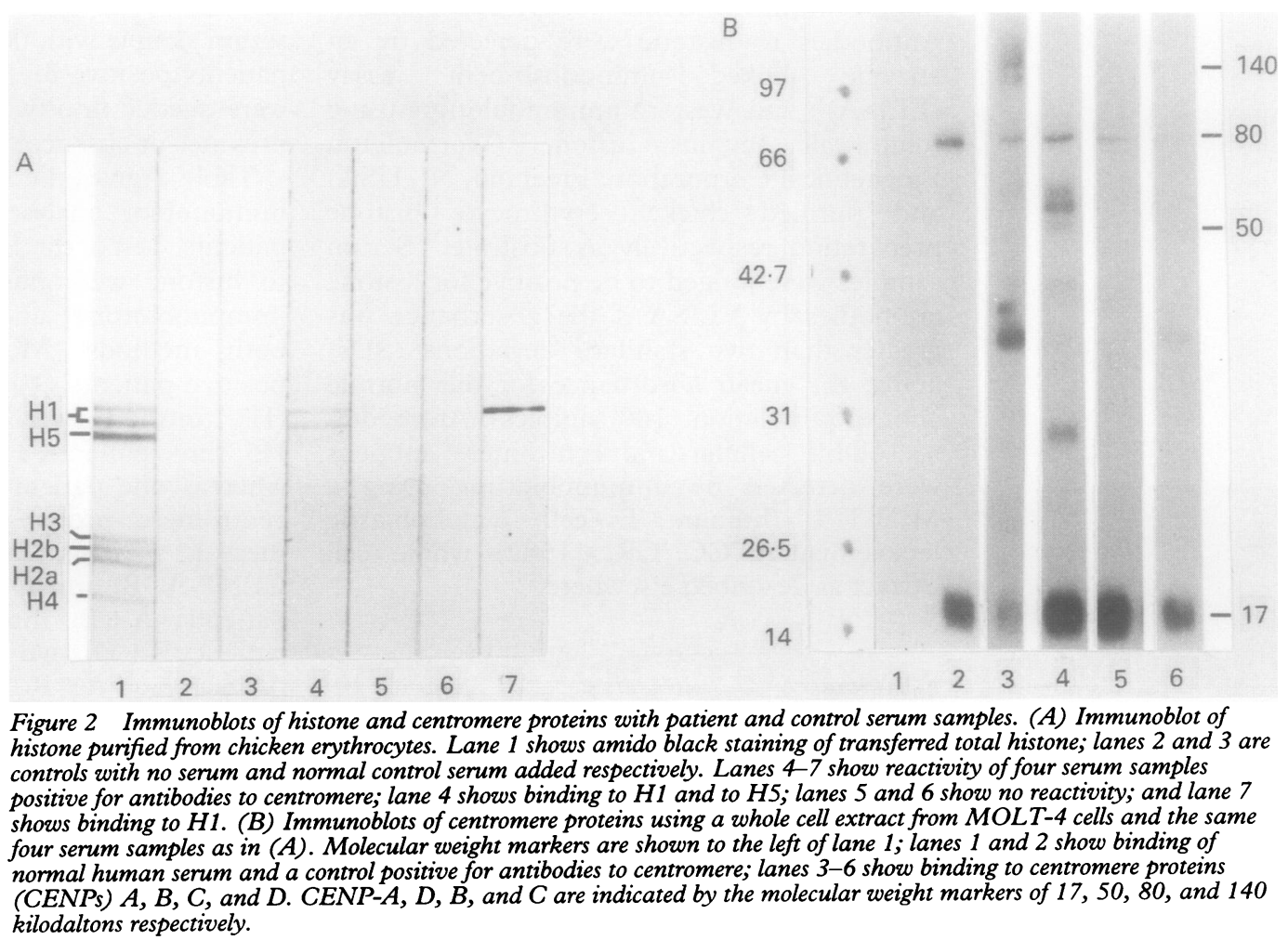


All five patients with the CREST variant with antibodies to centromere and histone were women who had at least three features of this disorder (table 1). Patients 5 and 6 reported dyspnoea on exertion but chest radiographs and complete pulmonary function tests were normal in the two subjects. The remaining three patients with CREST syndrome had no respiratory symptoms and had normal chest radiographs and pulmonary function tests. The remaining three patients in the antibodies to centromere/histone group had SLE, RA with Sjögren's syndrome, and cytopenia.

Each of the nine patients in the group with antibodies to centromere only who had the CREST variant had at least three features of the disease (table 1). The mean age of the group was 50.5 years (40-67 years) with a mean disease duration of 12.4 years (4-20 years). A further patient had an overlap syndrome with features of CREST and dermatomyositis. None of these patients had respiratory or cardiovascular symptoms or clinical findings. The four remaining patients in this group had Sjögren's syndrome, Raynaud's phenomenon, neutropenia, and a stroke.

\section{Discussion}

In the investigation of systemic rheumatic diseases, patients are often divided into subsets of disease based on clinical findings and the presence of a particular autoantibody. For example, antibodies to $\mathrm{Sm}$ are found in patients with SLE who tend to have a higher incidence of neurological disease, ${ }^{24}$ whereas antibodies to Jo-1 identify patients with polymyositis who have interstitial lung disease. ${ }^{25}$ Previous clinical studies of antibodies to centromere have shown that these antibodies are found in up to $96 \%$ of patients with the CREST variant of scleroderma when all five criteria are present ${ }^{6}$ and in up to $68 \%$ of patients when three or more criteria are applied. ${ }^{26}$ These patients tend to have a more prolonged disease course with less internal organ disease and less skin thickening. Antibodies to centromere are found in 4-10\% of patients with diffuse scleroderma, ${ }^{6-8} 27$ and a number of reports have suggested that this subset of patients also has less severe disease with less extensive skin thickening and visceral disease. ${ }^{8-10}$

In this study we report our clinical findings in 26 patients positive for antibodies to centromere who were identified from 1316 consecutive serum samples referred to our laboratory for autoantibody profiles. Twelve of these patients also had antibodies to histones, of whom four had diffuse scleroderma with severe pulmonary or vascular disease. Three of these four patients died as a result of pulmonary hypertension and right sided heart failure, and the fourth patient, who had severe peripheral vascular disease with digital autoamputation, survived a myocardial infarction. One of the three patients who died initially presented with SLE and subsequently dev- eloped diffuse scleroderma. Her antibody profile also changed when the disease diagnosis changed. Initially she had antibodies to RNP and $\mathrm{Sm}$ and only developed antibodies to centromere and histone when she developed scleroderma. Asherson et $a l^{28}$ reported three patients with coexistent SLE and scleroderma. One patient had discoid lupus with scleroderma, another had SLE with proximal skin thickening on the forearms without Raynaud's phenomenon, whereas the third patient had scleroderma with urticarial vasculitis, a positive Coombs' test (but with normal haemoglobin), and antibodies to DNA. Other reports of the coexistence of these two diseases by Dubois et $a l^{29}$ and Flores et $a l^{30}$ document the predominance of one or other disease in the patients. None of these patients was reported to have antibodies to centromere or histone. Our patient developed SLE with multisystem disease initially, and then diffuse scleroderma with skin and systemic disease.

Our study is the first to report the presence of antibodies to both centromere and histone in patients with scleroderma. We also show that, unlike other studies where antibodies to centromere are associated with a more benign disease course, ${ }^{6-10}$ that the presence of antibodies to centromere and histone is associated with a poor outcome in patients with diffuse scleroderma. Previous studies have shown a correlation between the antibodies to Scl-70 and pulmonary disease in diffuse scleroderma, ${ }^{8931}$ but none of our four patients had this antibody. The patients with CREST syndrome with antibodies to centromere and histone do not differ in their clinical presentation from those CREST patients with antibodies to centromere alone. Ongoing clinical observation will be necessary to determine if these patients are at risk for serious pulmonary or vascular complications. One other report ${ }^{32}$ describes the coexistence of antibodies to centromere and other autoantibodies, mitochondrial, smooth muscle, and Sjögren's syndrome antibodies, in patients with primary biliary cirrhosis, but there were no patients positive for antibodies to centromere with antibodies to histone and none of their patients had scleroderma.

Studies have shown that CENP-A has a solubility similar to histone, ${ }^{33}{ }^{34}$ that it copurifies with histones and nucleosomes, ${ }^{35}$ and that it shares sequence homology with $\mathrm{H} 3 .^{36}$ These observations have led to the suggestion that CENP-A is a centromere specific histone. In our study, the patients with antibodies to both centromere and histone did not react with H3 by immunoblotting, though most did react with CENP-A. In a previous study of centromere and histone antigens it was found that antibodies to centromere bound to and were absorbed by trout testis $\mathrm{H} 1$ and it was proposed that the centromeric antigens may be a variant of $\mathrm{H} 1 .{ }^{37}$ Our results show that certain serum samples positive for antibodies to centromere react with histone antigens, primarily $\mathrm{H} 1$ and the avian $\mathrm{H} 1$ variant, $\mathrm{H} 5$. These observations of the molecular characteristics of centromere and histone proteins 
taken together with our serological studies support the previous observations that antibodies to centromere and histone may share antigenic determinants.

In summary, we have described the coexistence of antibodies to centromere and histone in patients with scleroderma and identified a subset of patients with diffuse skin disease who have severe pulmonary or vascular disease. Our results contrast with those from previous clinical studies of antibodies to centromere, which have shown that this antibody is associated with a more benign disease course. One shortcoming of our study is that it is retrospective and it will be of interest to follow the clinical course of the other patients with scleroderma whom we have identified to see if they develop more pulmonary or vascular disease than those patients with antibodies to centromere alone.

Supported in part by grants from the Arthritis Society (LM) and the Medical Research Council of Canada (MJF). Dr Martin is an associate of the Arthritis Society.

1 Tan E M, Kunkel H G. Characteristics of a soluble nuclea antigen precipating with sera of patients with systemic lupus erythematosus. I Immunol 1966; 96: 464-71.

2 Douvas A S, Achten M, Tan E M. Identification of a nuclear protein $(\mathrm{Scl}-70)$ as a unique target of human antinuclea antibodies in scleroderma. F Biol Chem 1979; 254: 10514-22.

3 Fritzler M J, Tan E M. Antibodies to histone in druginduced and idiopathic lupus erythematosus. $\mathcal{F}$ Clin Invest $1978 ; 62: 560-7$.

4 Franco $\mathrm{H}$ L, Weston $\mathrm{W}$ L, Peebles C, Forstot S L, Phanuphak P. Autoantibodies directed against sicca syndrome antigens in neonatal lupus syndrome. $\mathcal{f} A m$ Acad Dermatol 1981; 4: 67-72.

5 Provost T T. Neonatal lupus. Arch Dermatol 1983; 119, 619-22.

6 Fritzler M J, Kinsella T D, Garbutt E. The CREST syndrome: a distinct serologic entity with anticentromer antibodies. Am F Med 1980; 69: 520-6.

7 Moroi M, Peebles C, Fritzler M J, Steigerwald J, Tan E M Autoantibodies to centromere (kinetochore) in scleroderma sera. Proc Natl Acad Sci USA 1980; 77 1627-31.

8 Catoggio L J, Bernstein R M, Black C M, Hughes G R V, Maddison P J. Serological markers in progressive systemic sclerosis: clinical correlations. Ann Rheum Dis 1983; 42. sclerosis:

9 Steen V D, Powell D L, Medsger T A Jr. Clinical correlations and prognosis based on serum autoantibodie in patients with systemic sclerosis. Arthritis Rheum 1988, 31: 196-203.

10 Weiner E S, Earnshaw W C, Senecal J-L, Bordwell B, Johnson P, Rothfield N F. Clinical associations of anticentromere antibodies and antibodies topoisomerase 1. Arthritis Rheum 1988; 31: 378-85.

11 Tan E M. Antinuclear antibodies: diagnostic markers for autoimmune disease and probes for cell biology. $A d v$ Immunol 1989; 44: 93-151.

12 Wasicek C A, Reichlin M. Clinical and serological differences between systemic lupus erythematosus patients with antibodies to Ro versus patients with

13 LeRoy E C, Black C, Fleischmajer R, et al. Scleroderma (systemic sclerosis): classification, subsets, an pathogenesis. F Rheumatol 1988; 15: 202-5.

14 Fritzler $M$ J, Tan E $M$. Antinuclear antibodies and the connective tissue diseases. In: Cohen A S, ed. Laboraton diagnostic procedures in rheumatic diseases. 3rd ed. New York: Grune and Stratton, 1985: 207-47.
15 Fritzler M J. Autoantibody testing: procedures and significance in systemic rheumatic diseases. In: Jasmin G,
Simard R, eds. Methods and achievements in experimental pathology. Vol 12. Basle: Karger, 1986: 224 60.

16 Ballou S P. Crithidia luciliae immunofluorescence test for antibodies to DNA. In: Rose N R, deMacario E C, Fahey J L, Friedman H, Penn G M, eds. Manual of clinical laboratory immunology. Washington: American Society for Microbiology, 1992: 730-4

17 Gohill J, Fritzler M J. Antibodies in procainamide-induced and systemic lupus erythematosus bind the C-terminus of histone (H1). Mol Immunol 1987; 24: 275--85.

18 Pauls J D, Silverman E, Laxer R M, Fritzler M J. Antibodies to histones $\mathrm{H} 1$ and $\mathrm{H} 5$ in sera of patients with juvenile rheumatoid arthritis. Arthritis Rheum 1989; 32: 877-83.

19 Alderuccio F, Chan E K L, Tan E M Molecular characterization of an autoantigen of $\mathrm{Pm}-\mathrm{Scl}$ in the and complete human cDNA encoding an apparent $75-\mathrm{kD}$ acidic protein of the nucleolar complex. F Exp Med 1991 173: $941-52$.

20 Arnett F C, Edworthy S M, Bloch D A, et al. The American Rheumatism Association 1987 revised criteria for the classification of rheumatoid arthritis. Arthritis Rheun 1988; 31: 315-24.

21 Tan E M, Cohen E S, Fries J F, et al. The 1982 revised criteria for the classification of systemic lupus criteria for the classification of systemic

22 Masi R T, Rodnan G P, Medgser T A, et al. Preliminary criteria for the classification of systemic sclerosis (scleroderma). Arthritis Rheum 1988; 23: 581-91.

23 Fritzler M J, Hart D A. Prolonged improvement of Raynaud's phenomenon and scleroderma after recombinant tissue plasminogen activator therapy. Arthritis Rheum 1990; 33: 274-6.

24 Winfield H G, Brunner C M, Koffler D. Serologic studies in patients with systemic lupus erythematosus and central nervous system dysfunction. Arthritis Rheum 1978; 21: nervous

25 Bernstein R M, Morgan S, Chapman H, et al. Anti-Joantibody: a marker for myositis with interstitial lung disease. $B M \mathcal{A}$ 1984; 289: $151-2$

26 Powell F C, Winkelmann R K, Venechie-Lemarchand F, Spurbeck J L, Schroeter A L. The anticentromere antibody: disease specificity and clinical significance. Mayo Clin Proc 1984; 59: 700-6.

27 Tan E M, Rodnan G P, Garcia I, Moroi Y, Fritzler M J, Peebles C. Diversity of antinuclear antibodies in progressive systemic sclerosis. Arthritis Rheum 1980; 23. 617-26.

28 Asherson R A, Angus H, Matthews J A, Meyers O, Hughe G R V. The progressive systemic sclerosis/systemic lupus overlap: an unusual clinical progression. Ann Rheum Dis overlap: an unusual

29 Dubois E L, Chandor S, Friou G J. Progressive systemic sclerosis and localized scleroderma (morphoea) with positive LE cell test and unusual systemic manifestation compatible with systemic lupus erythematosus. Medicin (Baltimore) 1971; 50: 192-222.

30 Flores R H, Stevens M B, Arnett F C. Familial occurrence of progressive systemic sclerosis and systemic lupus erythematosus. F Rheumatol 1984; 11: 321-3

31 Steen V D, Ziegler G L, Rodnan G P, Medsger T A. Clinical and laboratory associations of anticentromere antibody in patients with progressive systemic sclerosis. Arthritis patients with progressive

32 Moteki S, Yoshida H, Nishimaki T, Morito T. The significance of autoantibodies co-existing with anticentromere antibodies in the sera of patients with primary biliary cirrhosis. Rinsho-Byori 1990; 38: 888-94.

33 Valdivia M M, Brinkley B R. Fractionation and initial characterization of the kinetochore from the mammalian metaphase chromosomes. F Cell Biol 1985; 5: 1124-34.

34 Palmer D K, Margolis R L. Kinetochore components recognized by human autoantibodies are present on mononucleosomes. $\mathcal{F}$ Cell Biol 1985; 5: 173-86.

35 Palmer D K, O'Day K, Wener M H, Andrews B S, Margolis $\mathrm{R} \mathrm{L}$. A $17-\mathrm{kD}$ centromere protein (CENP-A) copurifies
with nucleosome core particles and with histones. $尹$ Cell with nucleosome core p

36 Palmer D K, O'Day K, Trong H L, Charbonneau H, Margolis R. Purification of the centromere-specific protein CENP-A and demonstration that it is a distinctive histone. Proc Natl Acad Sci USA 1991; 88: 3734-8.

37 Ayer L M, Fritzler M J. Anticentromere antibodies bind to trout testis histone 1 and a low molecular weight protein from rabbit thymus. Mol Immunol 1984; 9: 761-70. 